\title{
Using Learning Analytics to Support Engagement in Collaborative Writing
}

\author{
Ming Liu, Southwest University, Chongqing, China \\ Abelardo Pardo, School of Electrical and Information Engineering, The University of Sydney, Sydney, Australia \\ Li Liu, Chongqing University, Chongqing, China
}

\begin{abstract}
Online collaborative writing tools provide an efficient way to complete a writing task. However, existing tools only focus on technological affordances and ignore the importance of social affordances in a collaborative learning environment. This article describes a learning analytic system that analyzes writing behaviors, and creates visualizations incorporating individual engagement awareness and group ranking awareness (social affordance), and review writing behaviour history (technological affordance), to support student engagement. Studies examined the performance of the system used by university students in two collaborative writing activities: collaboratively writing a project proposal $(\mathrm{N}=41)$ and writing tutorial discussion answers $(\mathrm{N}=25)$. Results show that students agreed with what the visualization conveys and visualizations enhance their engagement in a collaborative writing activity. In addition, students stated that the visualizations were useful to help them reflect on the writing process and support the assessment of individual contributions.
\end{abstract}

\section{KEYWORDS}

Collaborative Writing, Group Awareness, Learning Analytics, Online Collaborative Writing Tools, Student Engagement, Visualization

\section{INTRODUCTION}

Writing is an important factor of teaching and learning in university settings, which cultivates students' self-expression, construction of identity, understanding and knowledge building (Galbraith, 1999). Writing has been mostly considered an individual learning activity. In recent years, collaborative writing has attracted many educational researchers' interests due to the discovery of new pedagogical benefits. As recent research initiatives illustrate, collaborative writing $(\mathrm{CW})$ can encourage students' initiative, creativity and critical thinking (Hodges, 2002); and help students to work jointly on shared objectives (Caspi and Blau, 2011). Some researchers also argue that participation in CW activities including online text-based discussions can assist students in becoming more competent knowledge workers (Ellis and Goodyear, 2010).

Research in the field of online collaborative writing (OCW) has largely emphasized on the efficiency of specific affordances, processes and conception. For example, how students use Google docs, Wikis and other OCW tools (Wheeler et al., 2008); how scripts and other process scaffolds improve the efficiency of group writing (Daemmrich, 2000); how synchronous communication and other additional technological tools enhance coordination or group awareness in OCW environments (Elola and Oskoz, 2010); and what are university students' conception of OCW (Limbu and Markauskaite, 2015). However, academics who attempt to embrace Online Collaborative Writing 
(OCW) in their teaching often report challenges that result in less positive student engagement or learning outcomes (Caspi and Blau, 2011; Cole, 2009). In addition, these challenges include the accurate assessment of individual contributions of the members within the student groups toward the final output (Roberts and McInnerney, 2007). In this study, we attempt to use learning analytics to generate useful visualizations to address these issues.

As research shows, a student who is engaged and intrinsically motivated in a task is more likely to learn from an activity. Fredricks et al (2004) defined engagement in three dimensions: behavioral, cognitive and emotional engagement. 'Behavioral engagement', which is the focus of the present study, refers to participation in school related activities and involvement in academic and learning tasks such as those being done online. It can be measured by observation and self-report. 'Cognitive engagement' refers to motivation, thoughtfulness and willingness to make an effort to comprehend ideas and master new skills. 'Emotional engagement' includes emotions and interest, such as affective reactions in the classroom towards teachers. These three aspects are interrelated and helpful to understand engagement as a whole. The term 'engagement' used throughout the paper, unless otherwise specified, refers to 'behavioral engagement'.

Compared with emotional and cognitive engagement, the measurement of behavioral engagement is more straightforward because behavioral patterns can be defined, observed and interpreted. For instance, when a student participates in an activity that is mediated by technology, a detailed collection of behavioral events can be recorded. Computer keystroke-logging (Bixler and D'Mello, 2013; Stromqvist and Malmsten, 1998) or screen capturing (Latif, 2008) allow a detailed account of the behavior of a writer including actions such as starting a new paragraph or deleting a text portion and these are all considered indicators of behavioral engagement. Thus, new computer technology permits the observation and identification of learning events, which can then be examined in relation to other indices of engagement. However, in order to collect the learning events, these computer technologies required some special software applications or hardware, such as ScriptLog (Stromqvist and Malmsten, 1998), installed in the student computer. These factors present a barrier to the use of this technology in the education sector.

New cloud-based technologies, such as Google Docs not only record the revision history (each revision contains the document content and timestamp) they also provide application programming interfaces (API) to access this information programmatically. In addition, Google Docs has the advantage of supporting easy system integration and synchronous collaborative writing and it has been successfully applied in student assignment management (Calvo et al., 2011), collaborative writing practices (Southavilay et al., 2013) and engagement visualization and measurement (Liu et al., 2013). Similar to Google Docs, Etherpad (www.etherpad.org) is a web-based collaborative realtime editor, which was acquired by Google in December 2009 and released as open source. It has many advantages, such as lightweight, quick to start up and easy to differentiate between different authors. We use the Etherpad to implement the collaborative writing environment.

This paper describes the development and evaluation of a new method to measure and visualize student behavioral engagement and patterns in a collaborative writing environment that was trialed with university students. In these studies participants were required to collaboratively complete writing tasks, a project proposal and tutorial discussion questions, while their writing activities were recorded using Etherpad. Computer-generated observations were processed and visualizations generated to yield estimations of the individual writer and group's level of engagement and illustrate the writing behavior patterns of individual writers. The visualizations for formative feedback are used to support student engagement during the writing activity while the visualization for summative feedback to support student reflection on the overall writing process after the writing activity.

The major contributions described in this paper are: 1) a novel learning analytic system that collects behavioral data of users' collaborative writing, estimates the level of engagement, and generates two types of visualizations, visualization for formative feedback and visualization for 
summative feedback; the study also examined 2) the performance of the system in two types of collaborative writing tasks, writing a project proposal and tutorial discussion.

The remainder of this paper is organized as follows: Section 2 describes the relevant work in the areas of behavioral engagement and learning analytics. Section 3 describes the architecture of the system used in the study. In section 4, the algorithms used to process the engagement measurements and the creation of the three types of visualizations is described. Sections 5 describe the research scenario and experimental study used to validate the proposed approach. The paper concludes in Section 6 with a discussion of the overall approach as well as lines for future exploration.

\section{BACKGROUND}

\subsection{Collaborative Writing}

Significant efforts have been made into studying the way the individual writes (Flower et al., 1989). Collaborative writing is that two or more people working together to produce a document with group responsibility for the end product, which is different from interactive writing (where people solicit others' opinions about their writings). The interest in collaborative writing research arose in the late 1980's (Beck, 1993). Research into collaborative writing has shown that it has great potential in scientific collaboration (Kraut et al., 1988), in second language learning (Storch, 2002), in producing technical reports (Noel and Robert, 2004) and in the development of scientific reasoning skills (Keys, 1994).

Researchers have investigated how people collaboratively write the document (Posner and Baecker, 1992; Sharples, 1993). Sharples et al. (1993) studied two types of collaborative writing strategies: sequential and parallel partition. In the sequential partition, the work is divided into sequential stages, and each stage is allocated to a different person or sub-group. In parallel partitioning, the document is divided into sections, and each person or sub-group works on a different section in parallel to the others. Posner and Becker investigated the collaborative writing process further and created taxonomy of collaborative writing with four dimensions: roles, activities, document control methods and writing strategies. Four roles were defined; writer (writes the document), consultant (offers information but does not participate in the document creation), editor (modifies the document) and reviewer (gives some advance to improve the document). Activities contain brainstorming, researching, planning, writing, editing, and reviewing. Document control refers to who manages the document during the writing. They identified four types of document control methods, centralized (one person controls the document), relay (one person at a time controls the document), independent (each person controls the section on which he/she is working), shared (everyone has equal access to the document). They further defined four types of writing strategies: (1) Single writer: one people writes while other group members play other roles; (2) Separate writer: each group member works on a different section, which is similar to parallel partition;(3) Joint writing: writers work together synchronously on the text; (4) Scribe: one person writes in a group meeting. They found that separate writer was the most effective collaborative writing strategy and joint writing the least effective. In our experiments, students mainly used the separate writer or parallel partition writing strategy with independent or shared document control method.

\subsection{Online Collaborative Learning and Writing Environment}

Literature on educational design states that well-designed tasks and learning environments can support productive learner behaviors and enhance engagement, positive learning experiences and outcomes (Jonassen and Land, 2012). However, there are many challenges in creating effective online collaborative learning and writing environments (Kirschner, 2004). Kirschner (2004) presents an affordance framework, including technological, educational and social affordances, for designing and evaluating such collaborative learning environment. Educational affordance refers to characteristics 
of the learning environment that facilitate collaborative learning behavior, which include group project management, group work co-construction, information, knowledge and feedback sharing. Technological affordance refers to characteristics that enable learners to accomplish learning tasks in an efficient and effective way. Bower (2008) further defined technological affordances in a second level of affordance categories: media (the ability to input and output various media forms, such as text and images), spatial (ability to resize, move or place contents within an interface), temporal (ability to access anytime anywhere as well as to record and play back information), navigation (ability to see other member's work), synthesis (ability to combine and integrate group members' input), and access-control (user management). Our current system captured all these features. Social affordance refers to features that offer social-contextual facilitation in relation to students' social interaction. It includes group communication and motivation. When learners perceive social affordances, they are encouraged to engage in activities (Kirschner, 2004). Dieberger (2000) considers awareness of other people's activities to be an essential ingredient for collaborative work.

Existing online collaborative writing tools, such as Google Docs and Wiki, have been designed to provide some basic functions of these three affordances. Several attempts have been made to enhance wikis with learning analytics (Hoefler and Guetl, 2011; Kubincová et al., 2012; Popescu et al., 2014). For example, Popescu (2014) developed a learning analytic tool, called CoLearn, which provides the visualization of timing of the students' contributions to helps instructors to analyze the collaborative writing strategies. In addition, it allows students to visualize their overall progress and comparative statistics with the group and class average. However, they focused on using learning analytics to support asynchronous collaborative writing and did not evaluate the usefulness of the visualizations. In this study, we focus on using the learning analytics to support the synchronous collaborative writing, where individual writers are aware of the rest of group members and other groups' engagement. In addition, different types of visualizations were evaluated in two empirical studies.

\subsection{Learning Analytics}

The area known as Learning Analytics (LA) has emerged as a result of behavior-related information available about how students learn. LA is defined as "the measurement, collection, analysis and reporting data about learners and their contexts, for purposes of understanding and optimizing learning and the environments in which it occurs" (Brown, 2012). In general, learning analytic systems can be divided into several modules, steps or phases (Campbell et al., 2007). One module captures detailed events such as the number and frequency of interactions with resources in a learning management system (Tanes et al., 2011; Waddington and Teasley, 2016). This module may also use additional factors such as a student's Grade Point Average (GPA) (Mckay et al., 2012), gender, etc. An algorithmic module then analyzes these data to infer some conclusions. These conclusions are reported back to users through an additional module. Typical reports include visualizations that can range from a simple traffic light-like display of overall student status and risks (Essa and Ayad, 2012; Tanes et al., 2011), to more sophisticated dashboards with detailed information about various aspects derived from the data (Rivera-Pelayo et al., 2013; Verpoorten et al., 2011). A more advanced module is often incorporated to suggest actions to modify the learning behaviors. These actions are sometimes referred to as interventions and may range from suggestions automatically proposed to instructors or other academic staff, to automatic adjustments applied on the experience.

The initial analytics tools designed within the context of learning experiences were pedagogically neutral. In other words, they simply provided insight about the events occurring in an environment without targeting any specific strategy. An example of these early tools is CourseVis (Mazza and Dimitrova, 2007), a platform to visually represent the interactions of students in the context of web-based distance education. The concept of dashboard appeared as a proposal to centralize the visualization of student events and foster self-reflection and sensemaking for both students and teachers (Verbert et al., 2013). At the same time, academic institutions started to use analytics to tackle the problem of student retention. Numerous institutions have created platforms that combine student 
interactions with other socio-economic factors to calculate the probability of a student dropping a course (Tanes et al., 2011). These platforms were later extended to cover the anticipation of other facts such as academic performance and are generally known as Early Warning Systems or EWAs (see (Fritz, 2011; Lonn et al., 2012) for two examples of these systems).

In the recent years, the pedagogical intent has been gaining influence in the design of learning analytics approaches. The emergence of constructivist approaches to education prompted the appearance of applications to analyze the interaction of users within the context of social networks. The work of Aviv et al. showed how to connect the topology emerging in a network with knowledge construction (Lonn et al., 2012). Visualizations are also used in this context to identify specific patterns and promote a more cohesive network (Aviv et al., 2003). More advanced approaches have been recently proposed in the context of discourse analysis (Ferguson and Shum, 2012, 2011; Ferguson et al., 2013). Nowadays, learning analytics attracted a great attention in the computer supported collaborative learning (CSCL) community, such as the use of learning analytics in a programming class (Berland et al., 2015), a pedagogical framework for learning analytics in collaborative inquiry tasks (Koh et al., 2016), group composition and performance prediction (Cen et al., 2016).

Tracer is a learning analytic system, which analyzes the information obtained from document revisions using Google Docs, and provides visualization and measurements for the level of engagement in an individual writing activity(Liu et al., 2013). The study results showed that the engagement time gauged by Tracer was moderately correlated to those reported by the students, and the generated visualization correctly conveys the student engagement. But, Tracer only focus on supporting individual writing.

This system described in this document can be considered as an extension of Tracer, which emphasize on generating visualizations for supporting student engagement in collaborative writing settings. Furthermore, we proposed an enhanced engagement measurement and a novel writing behavior detection algorithm for the visualizations.

\section{SYSTEM ARCHITECTURE}

Our learning analytics system ('Cooperpad') captures a detailed account of how a group of learners engage in a collaborative writing activity, estimates the individual and group engagement, detects the individual writing behavior and produces two types of feedback (formative and summative feedback visualization) to support engagement.

The three components of the system are shown in Figure 1. The first is the Data Collection Module which currently relies on the Etherpad. Etherpad is a highly customizable open source online editor providing collaborative editing in real time. The application records the text contents of all its pads, a list of users, their preferences and numerous intermediate versions of the documents while they are being modified, which are stored in Redis, a very fast in-memory key-value store. In each document revision, Etherpad keep track of user operations in the changeset (Theis et al., 2010), which is used for writing behavior detection by our system. The browser sends changesets to the server, which then sends them to the clients to update them. Changesets also get saved into the history of a pad which allows Etherpad to go back to every revision from the past. The application programming interface (API) is used by Cooperpad to access these information.

Currently, the system used the number of revisions, word count and writing behavior (e.g. add or delete text) to generate different types of visualizations since they are good indicators of behavioral engagement in a collaborative writing setting (Hoefler and Guetl, 2011; Popescu et al., 2014). For example, Hoefler and Guetl (2011) used the word count each group member has contributed to the assignment wiki and displayed this information in a contribution chart with the aim of motivating group members to contribute more. In addition, each group member's action (e.g. added text, removed test, edited text, and text changed style) on a revision of the assignment page is displayed to maintain 
task awareness. Similarly, Popescu et al. (2014) used the comparative statistics of the revision history information to enhance student competitiveness and involvement.

The second component of Cooperpad is the Data Analysis Module in which engagement measurement algorithms and writing behavior detector are implemented described in section 4.1 and 4.2. The third component is the Feedback Module described in section 4.3 where formative and summative feedback visualizations are created based on the results derived from the analysis phase.

\section{ENGAGEMENT MEASUREMENT ALGORITHM AND VISUALIZATIONS}

Due to the complexity of the data captured during the writing activity, it is challenging to produce a simple and meaningful visualization, such as group engagement ranking awareness and group member engagement awareness. Thus, raw events data are analyzed by the analysis model. This section describes the intensity-based engagement algorithm which is used for Individual Engagement Intensity Bar and Group Engagement Ranking Chart and Group Engagement Contribution Pie Chart Generation, and the writing behavior detection algorithm used for Writing Behavior Pattern Chart generation. The objective of these components was to explore how best to convey information to the user in an understandable format and enhance their engagement.

\subsection{Engagement Measurement Algorithm}

The engagement mentioned here refers to the behavioral engagement, specifically the time engagement of the student on the writing task, in other words, how much time the student spent on the task. The computation of the engagement is based on the timestamp information of each document revision. Our engagement measurement algorithms were based on the intuition that if the student is more engaged, the system generates more consecutive revisions; otherwise, the system produces less document revisions. In the previous study (Liu et al., 2013), we have proposed two engagement algorithms, point-based engagement and intensity-based engagement algorithm. The point-based algorithm simply sum up each data cluster, where each data cluster contains a set of data points (revisions with timestamp information) and a data cluster has a fixed threshold. For example, if the threshold is 1 minute, which means the time duration between the first data point and last data point is less than 1 minute. However, this algorithm does not incorporate engagement intensity, which could be useful for generating engagement intensity bar described in the following section.

The intensity-based algorithm sum up weighted time intervals between two adjacent revisions, where the weight refers to the engagement intensity (see Figure 2). If the time interval is smaller, the weight is bigger, which indicates that the engagement intensity is high. Based on our experience with

Figure 1. Cooperpad system architecture

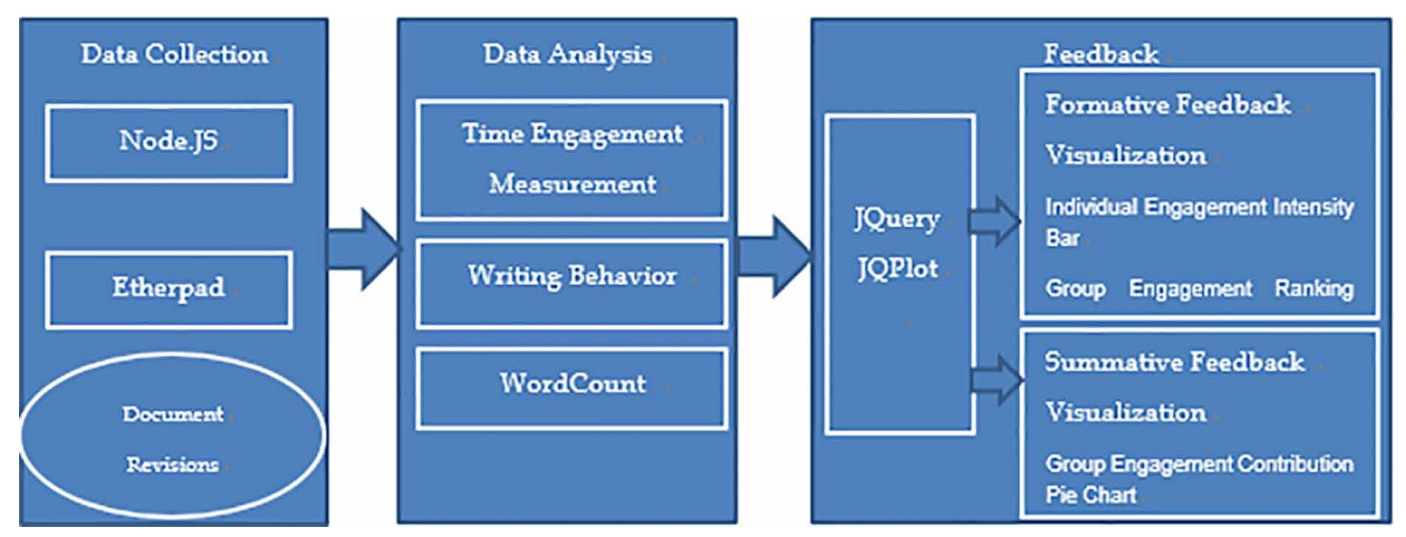


Figure 2. Intensity-based engagement measurement algorithm

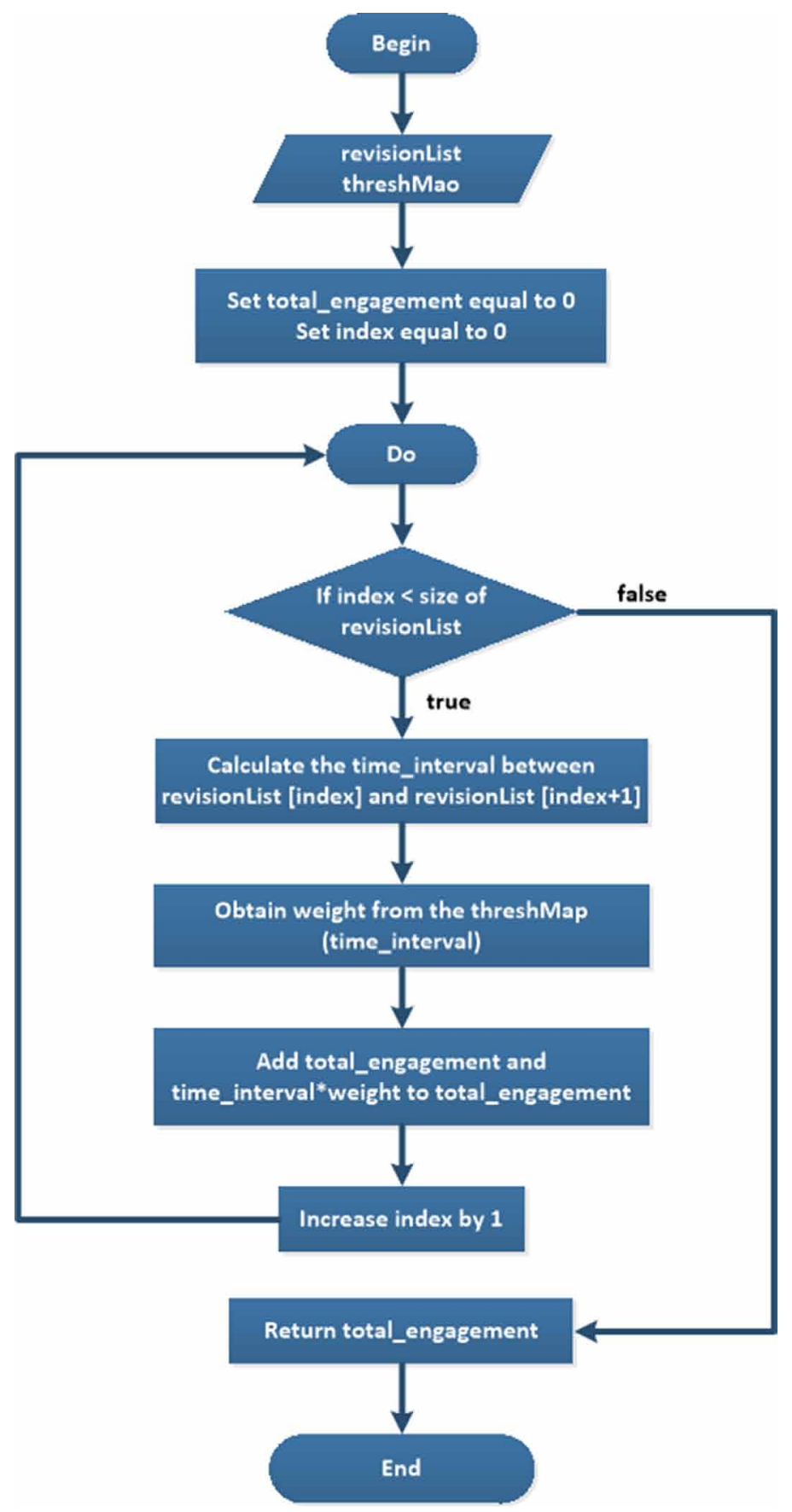

writing activities in learning situations, we store the following list of information for an intensive writing activity: (30s, 1), (45s, 0.8), (60s, 0.6), (75s, 0.4), (90s, 0.2). This list refers to the threshMap, where each element includes two values, time threshold for the interval between adjacent revisions and its corresponding weight. The weight indicates the engagement intensity or engagement level. 
For example, $(30 \mathrm{~s}, 1)$ means that if the time interval between adjacent revisions is greater than 0 but less than or equal to 30 seconds, the engagement level is 1 . Similarly, (45s, 0.8) shows that the engagement level is 0.8 if time interval is greater than 30 seconds but less than or equal to 45 seconds. This implies that the user almost constantly writes and the engagement level is high. But, if the time interval is greater than 90 seconds, the engagement intensity is zero. In order to display the engagement intensity bar more smoothly, described in section 4.3 , we used the five data points to derive a linear regression model, which further generates other 21 data points. Thus the total group engagement score is calculated as follows:

Engagement $=\sum_{\mathrm{j}}^{\mathrm{m}} \sum_{\mathrm{i}}^{\mathrm{n}} \mathrm{p}_{\mathrm{ji}} * \mathrm{w}_{\mathrm{i}}$

Where $\mathrm{j}$ is the index of group members and $\mathrm{m}$ is the size of group, $\mathrm{i}$ is the index of an adjacent revision pair, pji is the interval of the ith pair of adjacent revisions generated from member $\mathrm{j}$ and $\mathrm{Wi}$ is the weight assigned to this interval. As we mentioned before, the weight is determined by the duration of neighboring events (revisions). A small duration indicates a higher engagement level.

\subsection{Writing Behavior Detection}

Previous work in educational revision analysis (Fitzgerald, 1987; Connor and Asenavage, 1994) categorized revision changes to be either surface changes or text-based changes. With both categories, six kinds of changes were defined: (1) Addition: Adding a word or phrase; (2) Deletion: Omitting a word or phrase; (3) Substitutions: exchange words with synonyms; (4) Permutation: rearrange of words or phrases; (5) Distribution: one segment divided into two;(6) Consolidation: combine two segments into one.

Based on the Faigley's definition (1987), we defined only three primitives, addition, deletion and modification because automatically detecting other text operations, substitutions, permutation, distribution and consolidation, is not a trivial task, which requires more advanced technologies, such as natural language processing technology. So, we currently focused on detecting these three categories, which is more feasible. Modification indicates substitutions, permutation, distribution and consolidation. This definition is similar to Bronner (1994) and Zhang's work (2014).

A changeset (Theis et al., 2010) describes the difference between two revisions of the document. In the changeset of a revision, it contains three types of operators:,+- and $=$. The + operator adds text with attributes, and the - operator removes text, while the = operator does not change the text, but it may change the attributes of the text (e.g. make it bold). In addition, in the beginning of the changset string, it uses $<$ or $>$ to indicate if the word counts in current revision is greater or less than that of previous revision. For instance, this changeset Z:196 >1 I5=97 =31*4*5+1 \$” $x$ " shows that current revision has one more character than previous revision and contains three operators $(=$, $=,+)$. The last + operator add $\mathrm{x}$ to the document and make it bold. * I means applying an attribute to the following operator. Based on this definition, three regular expressions shown in Table 1 are defined to identify the writing behaviors, addition, deletion and modification.

The addition $/>[\wedge-\mid+]^{*} \backslash+/$ means current reversion has more text than previous revision and has only + operator. The deletion $\left./<^{\wedge}-\mid+\right]^{*}-/$ means current reversion has less text than previous revision and has only - operator. The modification $/\left[\langle>]\left[\wedge^{\wedge}-\mid+\right]^{*}-\left[{ }^{\wedge}-\backslash+\right]^{*} \backslash+/\right.$ means current reversion has - operator first, and then + operator at the end of operation.

\subsection{Visualizations}

This section presents different visualizations to provide formative feedback and summative feedback, which incorporates social awareness and technological awareness features, in a collaborative writing 
Table 1. Regular expression used in changeset for writing behavior detection

\begin{tabular}{|c|c|}
\hline Writing Behavior & Regular Expression \\
\hline Addition & $1>\left[{ }^{\wedge}-\mid+\right]^{*} \mid+/$ \\
\hline Deletion & $\left.1<{ }^{\wedge}-\mid+\right]^{*}-/$ \\
\hline Modification & $/[<>]\left[^{\wedge}-1+\right]^{*}-\left[^{\wedge}-1+\right]^{*} \mid+/$ \\
\hline
\end{tabular}

environment. In the formative feedback, the visualizations show the individual engagement intensity and the engagement ranking of this writing group in real time.

In the summative feedback, the visualizations show the overall engagement contributions and the writing behaviors of current group member in the entire writing activity.

\subsubsection{Formative Visualization Feedback}

In the Engagement Intensity Bar (EIB), each bar represents a group member's engagement intensity. $100 \%$ means fully engagement while 0 means not engaged at all. Figure 3 shows the current engagement levels of three writers. The EIB gives writers real-time feedback and makes them aware of other group member's engagement when they are writing. The individual engagement intensity is derived from the engagement algorithm.

In the Group Engagement Ranking Chart (GERC), the $\mathrm{x}$ axis represents the group name while $\mathrm{y}$ axis shows the total engagement time. It illustrates the group with highest engagement, the average engagement group and current engagement group. Figure 4 depicts that the IT Elite Team group got the highest engagement within a class and the current group almost reaches the average group engagement level. The GERC gives writers real-time feedback and makes them aware of other groups' engagement when they are writing.

\subsubsection{Summative Visualization Feedback}

After they finish the writing task, users can review their writing behavior patterns and total engagement contribution to help them to reflect on what they did (Technical Affordance). The Group Member Engagement Contribution Pie Chart (GMECPC) shows the percentage of each member engagement contribution in an entire writing task. Figure 5 shows that the whole writing assignment has been contributed by three students in a group, where a student Xuelian Li made the largest contribution $(51 \%)$.

Figure 3. Engagement intensity bar

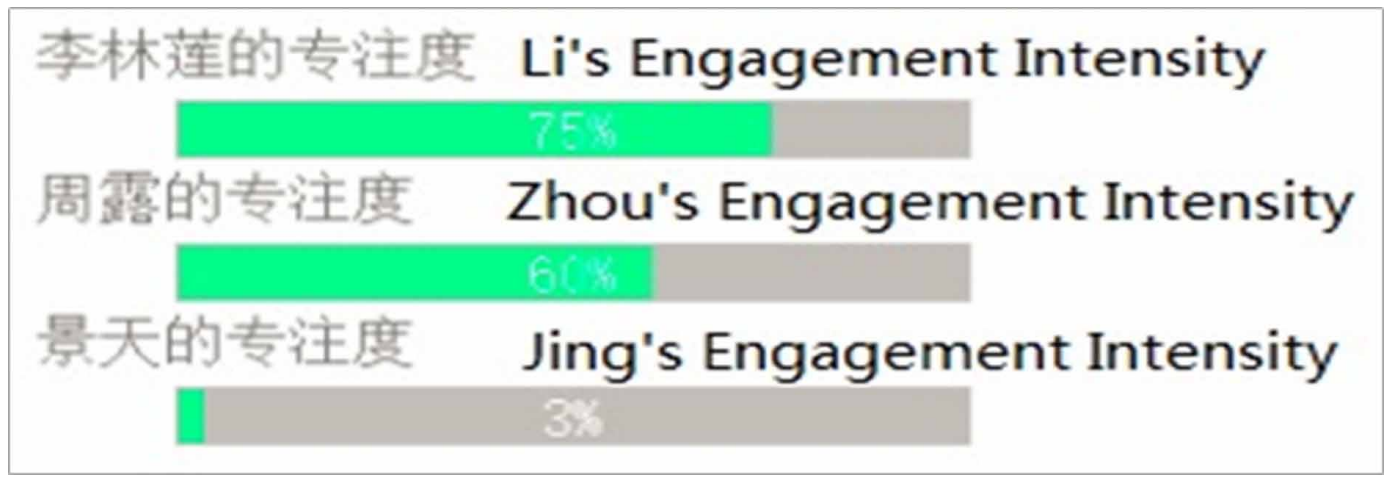


Figure 4. Group engagement ranking chart

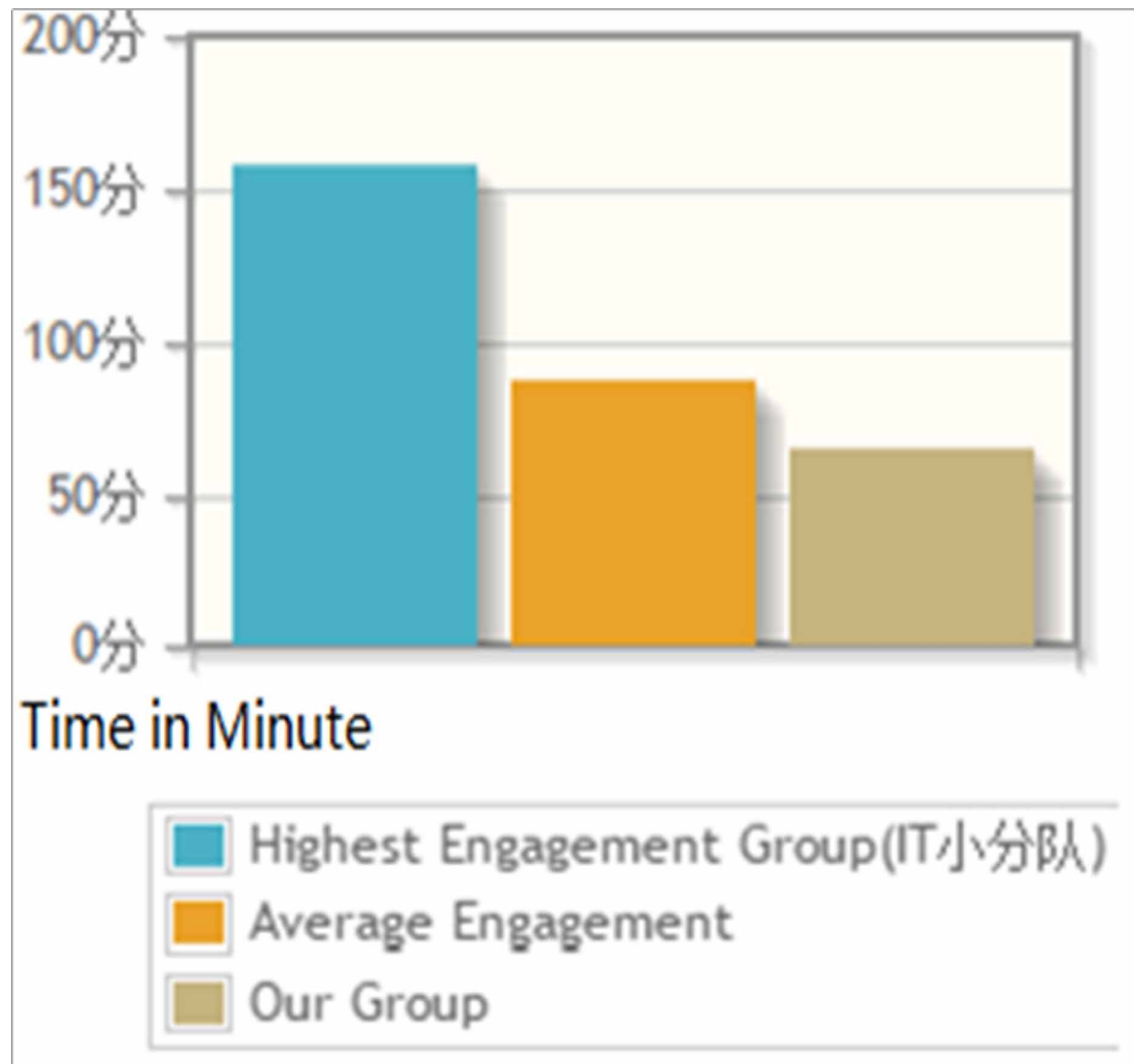

Figure 5. Group member engagement contribution pie chart

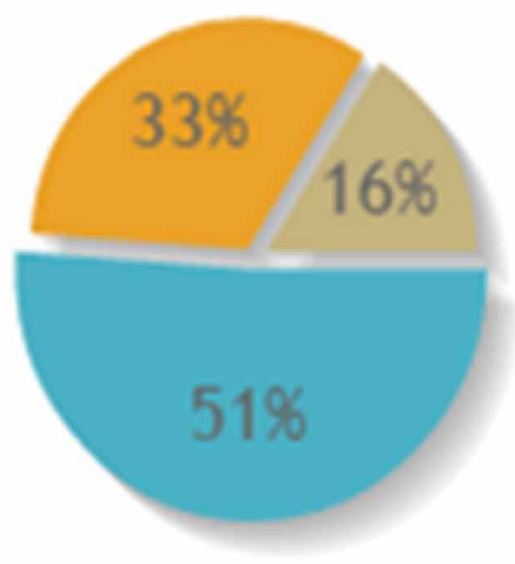

\section{Group Member Name}


In the Writing Behavior Pattern Chart (WBPC), each row represents a writer behavior patterns including add, delete and modify. Figure 6 shows that the behavioral pattern of an engineering student whilst completing a writing activity, where each point represents a writing behavior. We defined a green point as an addition behavior, a blue point as a modification behavior while a red point as a deletion behavior. The implemented visualization by using JQplot has a zoom in function which gives more detail about what the user has done in that operation.

In short, visualizations incorporated social affordance and technical affordance features for OCW. It provides feedback at different stage of writing. When the user is writing, it provides formative feedback with EIB and GERC, which provides each group member with their current engagement intensity and their current group engagement ranking position. When the user finished the writing, it gives summative feedback with GMECPC and WBPV, which allows writer to review their writing behavioral patterns and each group member engagement contribution in an entire collaborative writing activity.

The text editor is located in the middle of the screen and its content is collaboratively written by group members (the text color indicates which member wrote this text). The engagement intensity bars shown are on the left while the group engagement ranking chart below the bar.

\section{USER STUDIES}

Existing online collaborative writing tools focus on technical affordance and ignore the importance of social affordance to support engagement in collaborative writing. The system-generated visualizations by using learning analytics address these issues. In order to evaluate the effectiveness of the system, we conducted the following two studies in real collaborative writing activities of university courses.

\subsection{Study 1: Writing a Project Proposal}

\subsubsection{Participants and Procedure}

A total of 41 university students (male 35 and female: 6) participated in this study. Those student participants were third year software engineering students (age between 20 and 21), who came from Advanced Web Development class at a key university in China. They were allocated to different groups and asked to collaboratively write a project proposal during the lab session as one of the assessment in the course.

The project proposal includes the aim of project, key use cases, selection of application framework and data model. They had no prior knowledge of online collaborative writing tool and did not participated in any previous related study. The writing activity included brainstorming, planning, writing, editing and reviewing. In the brainstorming stage, group members got together to discuss what system they will build and wrote down the key features of the system in the Cooperpad. Then, in the planning section, one person outlined the structure of the document and assigned each group member to work on that section. Each person worked on one use case so that they can work in parallel, which

Figure 6. Writing behavior pattern chart

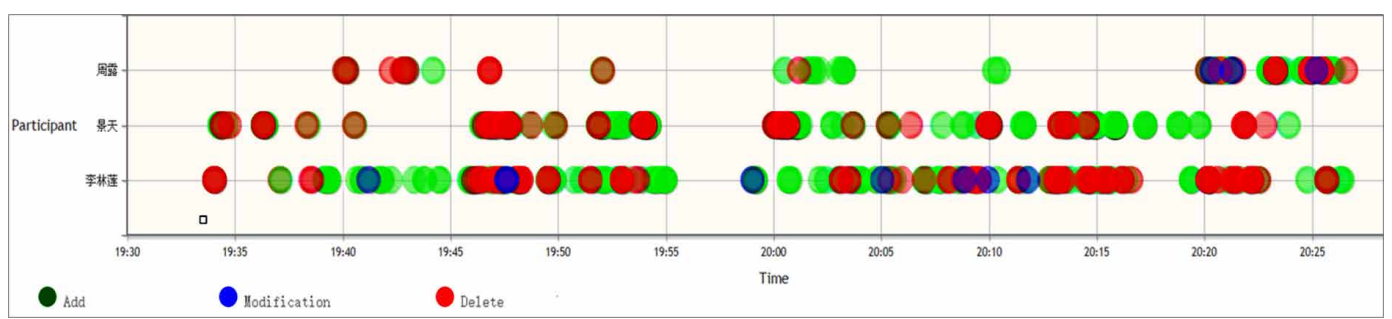


Figure 7. A screenshot of collaborative writing on a project proposal in the Cooperpad

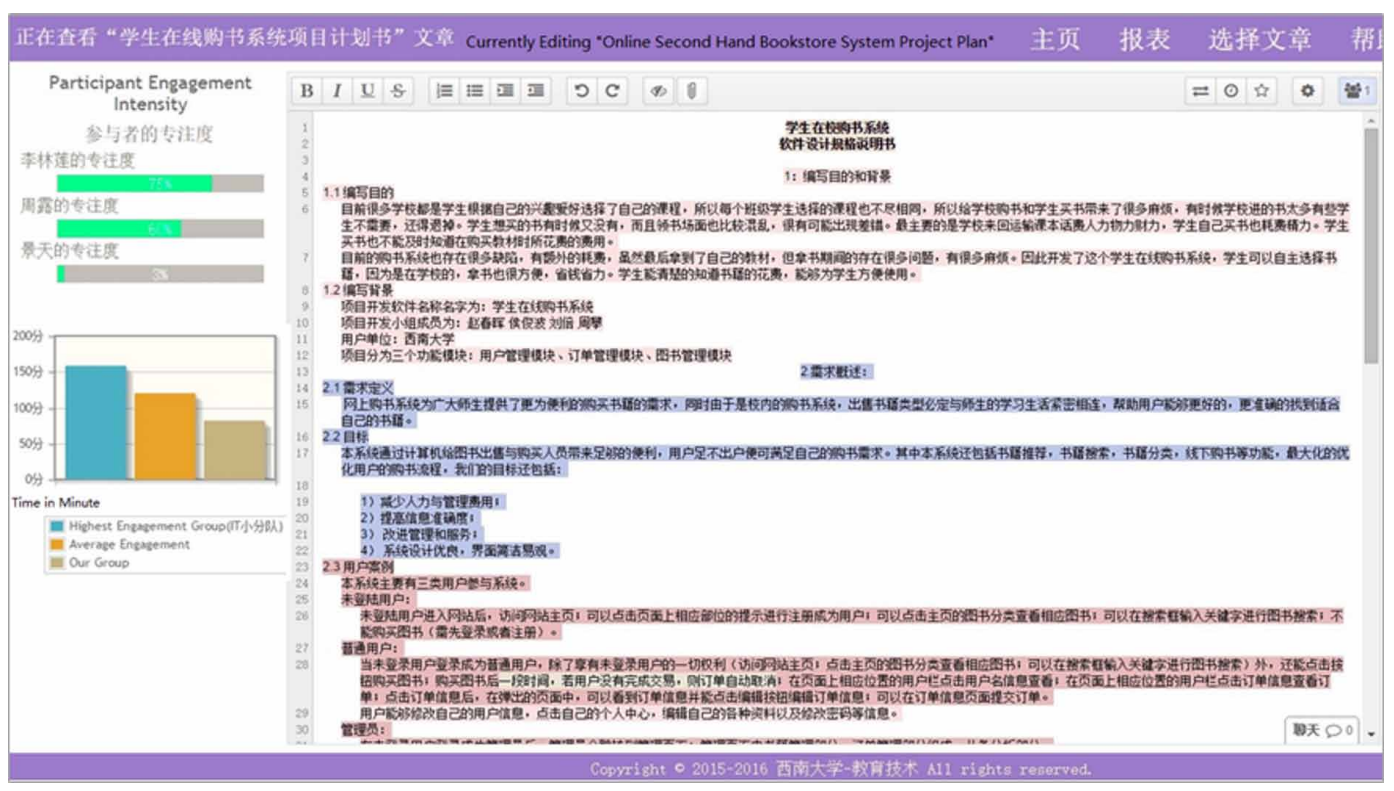

is quite similar to separate writer strategy. After finishing their own section, they gave and received suggestions in writing from peers. If they need communication, they can just talk to the person.

During the writing activity, Cooperpad generates formative feedback: EIB and GERC (see Figure 7). After the writing activity was finished, the system generated summative feedback: GMECPC and WBPC. At the conclusion of each study, each participant was asked to rate the quality of visualizations using a Likert scale, where 1 was "strongly disagree" and 5 was "strongly agree". Participants were asked the following quality measure $(\mathrm{QM})$ questions: QM1:I agree with what the visualization is showing; QM2a: The visualization enhances my engagement in a collaborative writing environment by being aware of group members' engagement (EIB); QM2b: The visualization enhances my engagement in a collaborative writing environment by being aware of group engagement ranking in the class (GERC); QM3: Useful to reflect on what I did; QM4: The visualization supports an assessment of individual contributions of the members within the student groups.

We classified each visualization as a feedback into formative feedback and summative feedback. EIB and GERC focused on generating feedback for enhancing engagement during the process of writing, so quality measure 1 and 2 are used for assessing this type of feedback. GMECPC and WBPC emphasized on generating feedback for reflection and work assessment after writing, thus quality measure 1, 3 and 4 are used for evaluating this type of feedback.

\subsubsection{Results}

Table 2 shows some descriptive statistics about the writing group. There are 12 groups containing 41 students in this class, where the average group size of writing a project proposal is 3.42 persons, while the average word count of a project proposal document is 1290.78 words. T able 3 illustrates the average scores reported by participants to the visualizations as a form of feedback on writing a project proposal. Regarding to formative feedback, the quality measure scores QM1 and QM2 were above 4 , indicating that most participants agreed that they understood what the visualizations were trying to convey and the visualization enhanced their engagement in a collaborative writing environment. EIB and GERC obtain similar high scores in QM1 (EIB: 4.02, GERC: 4.10) and QM2 (EIB: 4.16, GERC: 4.12). ANOVA revealed no statistical differences between the two visualizations (EIB and 
Table 2. Dataset description

\begin{tabular}{|c|c|c|c|c|}
\hline $\begin{array}{l}\text { Collaborative } \\
\text { Writing Task }\end{array}$ & Num.of Groups & Num.of Students & $\begin{array}{l}\text { Ave. Num. of } \\
\text { Persons Per Group }\end{array}$ & $\begin{array}{l}\text { Ave. Num. of Words } \\
\text { Per Group }\end{array}$ \\
\hline Project Proposal & 12 & 41 & 3.42 & 1290.78 \\
\hline
\end{tabular}

Table 3. Evaluation of visualization for writing a project proposal

\begin{tabular}{|c|c|c|c|c|}
\hline \multirow{2}{*}{ Quality Measure } & \multicolumn{2}{|c|}{ Formative Feedback } & \multicolumn{2}{|c|}{ Summative Feedback } \\
\hline & EIB & GERC & GMECPC & WBPC \\
\hline QM1: I agree with what the visualization is showing. & $\begin{array}{c}\mathrm{M}=4.02 \\
\mathrm{SD}=0.59 \\
\mathrm{~N}=41\end{array}$ & $\begin{array}{c}\mathrm{M}=4.10 \\
\mathrm{SD}=0.42 \\
\mathrm{~N}=41\end{array}$ & $\begin{array}{c}\mathrm{M}=4.51 \\
\mathrm{SD}=0.61 \\
\mathrm{~N}=41\end{array}$ & $\begin{array}{c}\mathrm{M}=4.13 \\
\mathrm{SD}=0.18 \\
\mathrm{~N}=41\end{array}$ \\
\hline $\begin{array}{l}\text { QM2: The visualization enhances my engagement in a } \\
\text { collaborative writing environment by being aware of group } \\
\text { members' engagement or group engagement ranking in the } \\
\text { class }\end{array}$ & $\begin{array}{c}\mathrm{M}=4.16 \\
\mathrm{SD}=0.32 \\
\mathrm{~N}=41\end{array}$ & $\begin{array}{c}\mathrm{M}=4.12 \\
\mathrm{SD}=0.31 \\
\mathrm{~N}=41\end{array}$ & & \\
\hline QM3: Useful to reflect on what I did & & & $\begin{array}{c}\mathrm{M}=2.58 \\
\mathrm{SD}=0.98 \\
\mathrm{~N}=41\end{array}$ & $\begin{array}{c}\mathrm{M}=3.95 \\
\mathrm{SD}=0.12 \\
\mathrm{~N}=41\end{array}$ \\
\hline $\begin{array}{l}\text { QM4: The visualization supports an assessment of individual } \\
\text { contributions of the members within the student groups. }\end{array}$ & & & $\begin{array}{c}\mathrm{M}=4.18 \\
\mathrm{SD}=0.78 \\
\mathrm{~N}=41\end{array}$ & $\begin{array}{c}\mathrm{M}=3.20 \\
\mathrm{SD}=0.38 \\
\mathrm{~N}=41\end{array}$ \\
\hline
\end{tabular}

GERC), $F(1,39)=0.12, p>0.05$ in QM1 and $F(1,39)=0.10, p>0.05$ in QM2. These results indicated that the EIB was as useful as the GERC for supporting engagement in collaborative writing.

For summative feedback (see Table 3), the average scores for GMECPC and WBPC in QM 1 were above 4 , indicating those participants agreed with what the visualizations are showing. In QM 3 , the average score for GMECPC is less than three, which indicate that those participants disagree with the usefulness for reflection on what they did. Based on the feedback from the students, the main reason is that this chart only simply provides an overall contribution of each group member to a writing task and do not reveal help them to reflect their whole writing process. One possible better chart should show their engagement history during the whole writing process, where the $\mathrm{x}$-axis is time and $y$-axis is the engagement level. In this case, the student can see their engagement during the whole writing process. On the contrary, the mean score for WBPC is 3.95, which indicates that participants almost agreed that WBPC was useful for reflection. It was found that WBPC significantly outperformed GMECPC, $\mathrm{F}(1,39)=0.21, \mathrm{p}<0.05$. However, GMECPC $(\mathrm{M}=4.18)$ is more useful than WBPC $(M=3.20)$ regarding to the assessment of individual contributions.

We also examined the relationship between the group engagement measure by the system and score given by the teacher based on the quality of this group's project proposal (two main factors: document presentation and technical feasibility). Table 4 shows the Pearson correlation coefficient is .53 with $\mathrm{p}<0.05$, indicating there is a significant moderate correlation between group engagement measured by the system and scores for this group writing task.

\subsection{Study 2: Writing Tutorial Discussion Answers}

\subsubsection{Participants and Procedure}

A total of 35 university students participated (male: 24 and female: 11$)$ and those student participants were second year software engineering students (age between 19 and 20), who came from System 
Table 4. Pearson Correlation between Student Engagement and Scores for the project proposal assignment

\begin{tabular}{|c|c|}
\hline & Group Engagement \\
\hline Score & $\begin{array}{c}.53(\mathrm{n}=12) \\
\mathrm{p}<0.05\end{array}$ \\
\hline
\end{tabular}

Analysis and Design class at Southwest University. They were allocated to different groups and asked to collaboratively write the answers about functional modeling during the tutorial session about 80 minutes. Because this course is bilingual teaching course and those content is primarily taught in English. Therefore, the tutorial discussion questions and answers were both in English. We found that two types of writing strategies were used by students. Three groups of students collaboratively work on the same question (joint write). Each person first tried to come up a solution for each question and wrote down their answers in the Cooperpad. Then, they combined their answers together. Other four groups of students first divided the task and work on individual questions (separate write). If they need communication, they can just talk to the person. Their common writing goal is to find the solutions for tutorial questions. They spent about 40 minutes in writing. The student informational sources are based on lecture slides. They checked the lecture slides when they have problems in finding the solution. Similar to study 1, we used the quality measurements to evaluate the systemgenerated visualization.

An example of tutorial questions is shown below:

Review the Amazon.com Web site. Develop the requirements definition for the site. Create a list of functional business requirements that the system meets. What different kinds of nonfunctional business requirements does the system meet? Provide examples for each kind. Suppose that you are going to build a new system that automates or improves the interview process for the Career Services Department of your school. Develop a requirements definition for the new system. Include both functional and nonfunctional system requirements. Pretend you will release the system in three different versions. Prioritize the requirements accordingly. Suppose you are the analyst charged with developing a new system for the university bookstore with which students can order books online and have them delivered to their dorms and off-campus housing. What requirements-gathering techniques will you use? Describe in detail how you would apply the techniques.

\subsubsection{Results}

Table 5 describes some descriptive statistics about this writing activity. The average group size in a tutorial discussion is 5 persons, and the average word count of the tutorial discussion is 892 words. Table 6 shows the average scores rated by student participants working on the tutorial discussion. With respect to formative feedback, the average scores in both QM1 and QM2 were above 4, indicating that most participants agreed that they understood what the visualizations were trying to convey and the visualization enhanced their engagement in a collaborative writing environment. EIB were as useful as GERC in both quality measures.

For the summative feedback, the average scores for GMECPC and WBPC in QM 1 were above 4 , indicating those participants agreed with what the visualization are showing. The average scores for GMECPC was just 3.03, indicating that those participants keep neutral opinion about the

Table 5. Dataset description

\begin{tabular}{|c|c|c|c|c|}
\hline $\begin{array}{c}\text { Collaborative Writing } \\
\text { Task }\end{array}$ & $\begin{array}{c}\text { Num.of } \\
\text { Groups }\end{array}$ & Num. of Students & $\begin{array}{c}\text { Ave. Num. of } \\
\text { Persons Per Group }\end{array}$ & $\begin{array}{c}\text { Ave. Num. of Words } \\
\text { Per Group }\end{array}$ \\
\hline Tutorial Discussion & 7 & 35 & 5 & 892 \\
\hline
\end{tabular}


Table 6. Evaluation of visualization for working on tutorial discussion

\begin{tabular}{|l|c|c|c|c|}
\hline \multirow{2}{*}{ Quality Measure } & Formative Feedback & \multicolumn{2}{c|}{ Summative Feedback } \\
\cline { 2 - 5 } & EIB & GERC & GMECPC & WBPC \\
\hline & $\mathrm{M}=4.36$ & $\mathrm{M}=4.29$ & $\mathrm{M}=4.35$ & $\mathrm{M}=4.06$ \\
QM1: I agree with what the visualization is showing. & $\mathrm{SD}=0.80$ & $\mathrm{SD}=0.96$ & $\mathrm{SD}=0.41$ \\
$\mathrm{~N}=35$ & $\mathrm{~N}=35$ & $\mathrm{~N}=35$ & $\mathrm{~N}=35$ \\
\hline & $\mathrm{M}=4.67$ & $\mathrm{M}=4.26$ & & \\
QM2: The visualization enhances my engagement in a & $\mathrm{SD}=0.49$ & $\mathrm{SD}=0.96$ & & \\
collaborative writing environment. & $\mathrm{N}=35$ & $\mathrm{~N}=35$ & & \\
\hline & & & $\mathrm{M}=3.03$ & $\mathrm{M}=4.15$ \\
QM3: Useful to reflect on what I did & & & $\mathrm{SD}=0.18$ & $\mathrm{SD}=1.00$ \\
& & & $\mathrm{~N}=35$ & $\mathrm{~N}=35$ \\
\hline $\begin{array}{l}\text { QM4: The visualization supports an assessment of } \\
\text { individual contributions of the members within the student } \\
\text { groups. }\end{array}$ & & $\mathrm{M}=4.48$ & $\mathrm{M}=3.35$ \\
& & $\mathrm{SD}=0.25$ & $\mathrm{~N}=35$ \\
$\mathrm{~N}=35$ \\
\hline
\end{tabular}

usefulness for reflection. The average score for WBPC $(M=4.15)$ in QM 3 is higher than which of GECPR, demonstrating that those participants agree with the usefulness for reflection. Regarding to the assessment of individual, the average score $(\mathrm{M}=4.48)$ obtained for GMECPC was higher than that of WBPC $(M=3.35)$. These results were almost consistent with the results obtained in study 1 .

In short, the results of both studies show that:

- Writers agreed with what the formative feedback visualizations showed (agreement 4.02-4.10 in study 1 while agreement 4.29-4.36 in study 2)

- Writers agreed with what the summative feedback visualizations showed (agreement 4.13-4.51 in study 1 while agreement 4.06-4.35 in study 2)

- Writers agreed that the formative feedback visualization supported my engagement in a collaborative writing environment (agreement 4.12-4.16 in study 1 while agreement 4.26-4.67 in study 2)

- Writers found that the writing behavior pattern chart was useful to reflect on (agreement 3.95 in study 1 while agreement 4.15 in study 2 )

- Writers found that the group member engagement contribution pie chart was useful to supports an assessment of individual contributions of the members within the student groups. (Agreement 4.18 in study 1 while agreement 4.48 in study 2)

\subsection{Student Interview}

In addition to the questionnaire, a face-to-face interview with student participants in both classes has been conducted to get an understanding of student experience of using Cooperpad. The overall feedback from the students was very positive. First of all, most of students like the efficiency of the collaborative writing tool.

For example, "it is more effective to finish the task". "It does not have location limitations, everyone can easily contribute to the discussion. "Compared with traditional tutorial discussion, this way to discussion is more organized and effective since you can directly write and share your thoughts with your team mates and the discussion results are clearer."

Secondly, the visualization helps them get more engaged in the task.

For example, it is easy to use and motivates me to get more engaged in the task by being aware of others' engagement.

Lastly, the collaborative writing tool is particularly useful in tutorial discussion for those students with poor oral communication skill. 
For example, it provides equal opportunity for everyone to express their ideas through writing the answers on the Cooperpad during the joint writing, which is particularly true for those students who are very shy and not good at English.

However, some issues were raised by student participants. For example, this online editor does not support drawing graphs. Addition, this tool cannot capture my engagement if I am orally discussing with my teammate.

\section{DISCUSSION AND CONCLUSION}

Existing collaborative writing tools cannot track and measure student engagement, evaluate individual contribution and provide feedback to support collaborative writing (Roberts and McInnerney, 2007). This study attempted to automatically capture the student behavior during a collaborative writing task by developing Cooperpad, a novel Learning Analytic system which uses Etherpad API to collect the document's revisions, then analyses them and generates quantitative and visual measures of behavioral engagement and pattern over time to support their engagement and individual assessment. These visualizations successfully illustrated Kirschner's an affordance framework, including social affordance and technological affordance, for designing and evaluating such collaborative learning environment (Kirschner, 2004).

The system was evaluated in two different collaborative writing tasks, writing a project proposal and tutorial discussion, from university courses. The visualization evaluation results show that the average quality measure scores QM1 and QM2 were above 4 in both studies. It indicated that writers agreed with what the visualizations conveyed and showed. In addition, the average scores for writing behavior pattern chart in QM3 were above 3.95 in both studies, which indicates that the participants almost agree that the visualization was useful to reflect on, while the average scores for group member engagement contribution chart were above 4.18 , which implied that the participants agree that the visualization supports an assessment of individual contributions of the members within the student groups. Furthermore, it has found that the correlation between the engagement measured by the system and the scores given by the teacher in study 1 is moderate $(\mathrm{r}>.50)$. This result is in consistent with previous findings which show that student engagement is positively correlated to college students' grade point average scores (Casuso-Holgado et al., 2013).

Our current system lacks of a good communication channel, such as an online chat function, during collaboration, which is a useful feature for social affordance. Having this feature allows us to capture more communication information and it could improve the accuracy of the engagement measurement algorithm and visualization. Moreover, both studies were conducted in a classroom, where the writing groups were co-located and the participants were university students with advanced computer skills.

In future work, we will evaluate this tool from various aspects, such as user experience and colocation of writing groups. Besides, we will include engagement estimations that consider additional dimensions of writing, including the quality of content, word count and changes made. Furthermore, we will investigate the technological and social awareness further: how the tool facilitates social awarenesses and to what level.

\section{ACKNOWLEDGMENT}

This work is supported by Chongqing Social Science Planning Fund Program under grant No. 2014BS123, Fundamental Research Funds for the Central Universities under grant No. SWU114005, XDJK2017C024, XDJK2017D064, CQU903005203326, and National Natural Science Foundation of China (61502397), and the Scientific Research Foundation for the Returned Overseas Chinese Scholars, State Education Ministry, and the Research Program Funds of Faculty of Education, at Southwest University (Learning Technology Assisted Writing Research Project). 


\section{REFERENCES}

Aviv, R., Erlich, Z., Ravid, G., \& Geva, A. (2003). Network analysis of knowledge construction in asynchronous learning networks. Journal of Asynchronous Learning Networks, 7, 1-23.

Beck, E. E. (1993). A Survey of Experiences of Collaborative Writing. In Sharples (Ed.), Computer Supported Collaborative Writing (pp. 87-112). doi:10.1007/978-1-4471-2007-0_6

Berland, M., Davis, D., \& Smith, C. P. (2015). AMOEBA: Designing for collaboration in computer science classrooms through live learning analytics. Int. J. Comput. Collab. Learn., 10(4), 425-447. doi:10.1007/s11412015-9217-z

Bixler, R., \& D'Mello, S. (2013). Detecting Boredom and Engagement During Writing with Keystroke Analysis Task Appraisals, and Stable Traits. Proceedings of the 2013 International Conference on Intelligent User Interfaces (pp. 225-233). doi:10.1145/2449396.2449426

Bower, M. (2008). Affordance analysis - matching learning tasks with learning technologies. Educational Media International, 45(1), 3-15. doi:10.1080/09523980701847115

Brown, M., 2012. Learning Analytics: Moving from Concept to Practice. Educ. Learn. Initiat. Br.

Calvo, R. A., ORourke, S. T., Jones, J., Yacef, K., \& Reimann, P. (2011). Collaborative writing support tools on the cloud. IEEE Trans. Learn. Technol., 4(1), 88-97. doi:10.1109/TLT.2010.43

Campbell, J. P., DeBlois, P. B., \& Oblinger, D. G. (2007). Academic Analytics: A New Tool for a New Era. Educational Review, 42, 40-57.

Caspi, A., \& Blau, I. (2011). Collaboration and psychological ownership: How does the tension between the two influence perceived learning? Social Psychology of Education, 14(2), 283-298. doi:10.1007/s11218-010-9141-z

Casuso-Holgado, M. J., Cuesta-Vargas, A. I., Moreno-Morales, N., Labajos-Manzanares, M. T., Barón-López, F. J., \& Vega-Cuesta, M. (2013). The association between academic engagement and achievement in health sciences students. BMC Medical Education, 13(1), 33. doi:10.1186/1472-6920-13-33 PMID:23446005

Cen, L., Ruta, D., Powell, L., Hirsch, B., \& Ng, J. (2016). Quantitative approach to collaborative learning: Performance prediction, individual assessment, and group composition. Int. J. Comput. Collab. Learn., 11(2), 187-225. doi:10.1007/s11412-016-9234-6

Cole, M. (2009). Using Wiki technology to support student engagement: Lessons from the trenches. Computers \& Education, 52(1), 141-146. doi:10.1016/j.compedu.2008.07.003

Connor, U., \& Asenavage, K. (1994). Peer response groups in esl writing classes: How much impact on revision? Journal of Second Language Writing, 3(3), 257-276. doi:10.1016/1060-3743(94)90019-1

Daemmrich, I. G. (2000). An Analysis of the Current Chinese Characters Similar in Form. J. Southwest Norm. Univ (26th ed., pp. 12512-12519). Humanities Socail Sci.

Dieberger, A. 2000. Where did all the people go? A collaborative web space with social navigation information. Proceedings of the 9th International World Wide Web Conference, Amsterdam.

Ellis, R. A., \& Goodyear, P. (2010). Students' experiences of E-learning in higher education: The ecology of sustainable innovation. New York: Routledge.

Elola, I., \& Oskoz, A. (2010). Collaborative writing: Fostering foreign language and writing conventions development. Language Learning \& Technology, 14, 51-71.

Essa, A., \& Ayad, H. (2012). improving student success using predictive models and data visualisations. Proceedings of the 19th Association for Learning Technology Conference (pp. 58-70). doi:10.3402/rlt. v20i0.19191

Ferguson, R., \& Shum, S. B. (2011). Learning analytics to identify exploratory dialogue within synchronous text chat. Proceedings of the 1st International Conference on Learning Analytics and Knowledge LAK'11. New York: ACM Press. doi:10.1145/2090116.2090130 
Ferguson, R., \& Shum, S. B. (2012). Social Learning Analytics: Five Approaches. Proceedings of the 2nd International Conference on Learning Analytics and Knowledge LAK '12. New York: ACM Press. doi:10.1145/2330601.2330616

Ferguson, R., Wei, Z., He, Y., \& Buckingham Shum, S. (2013). An evaluation of learning analytics to identify exploratory dialogue in online discussions. Proceedings of the Third International Conference on Learning Analytics and Knowledge LAK '13. New York: ACM Press. doi:10.1145/2460296.2460313

Fitzgerald, J. (1987). Research on Revision in Writing. Review of Educational Research, 57(4), 481-506. doi:10.3102/00346543057004481

Flower, L., Schriver, K.A., Carey, L. (1989). Planning in writing: The cognition of a constructive process.

Fredricks, J. A., Blumenfeld, P. C., \& Paris, A. H. (2004). School Engagement: Potential of the Concept, State of the Evidence. Review of Educational Research, 74(1), 59-109. doi:10.3102/00346543074001059

Fritz, J. (2011). Classroom walls that talk: Using online course activity data of successful students to raise self-awareness of underperforming peers. The Internet and Higher Education, 14(2), 89-97. doi:10.1016/j. iheduc.2010.07.007

Galbraith, D. (1999). Writing as a knowledge-constituting process. In Knowing What to Write: Conceptual Processes in Text Production (pp. 139-160). Amsterdam: Amsterdam University Press.

Hodges, G. C. (2002). Learning through collaborative writing. Reading, 36, 4-10.

Hoefler, M., \& Guetl, C. (2011). Enhancing Wikis with Visualization Tools to Support Groups Production Function and to Maintain Task and Social Awareness. Procs. ICBL 1-6.

Jonassen, D., \& Land, S. (2012). Theoretical Foundations of Learning Environments (2nd ed.). Routledge.

Keys, C. W. (1994). The Development of Scientific Reasoning Skills in Conjunction with Collaborative Writing Assignments: An Interpretive Study of Six Ninth-Grade Students. Journal of Research in Science Teaching, 31(9), 1003-1022. doi:10.1002/tea.3660310912

Kirschner, P. A. (2004). Design, development, and implementation of electronic learning environments for collaborative learning. Educational Technology Research and Development. doi:10.1007/BF02504674

Koh, E., Shibani, A., Tan, J. P., \& Hong, H. (2016). A Pedagogical Framework for Learning Analytics in Collaborative Inquiry Tasks: An Example from a Teamwork Competency Awareness Program. Proc. LAK16 6th Int. Conf. Anal. Knowl. (pp. 74-83). doi:10.1145/2883851.2883914

Kraut, R., Egido, C., \& Galegher, J. (1988). Patterns of contact and communication in scientific research collaboration. Proceedings of the 1988 ACM Conference on Computer-Supported Cooperative Work CSCW '88 (pp. 1-12). doi:10.1145/62266.62267

Kubincová, Z., Homola, M. B., \& Janajev, R. (2012). Tool-supported assessment of wiki-based assignments. Proceedings of the 4th International Conference on Computer Supported Education (pp. 58-67).

Latif, M. M. A. (2008). A state-of-the-art review of the real-time computer-aided study of the writing process. Int. J. English Stud., 8, 29-50.

Limbu, L., \& Markauskaite, L. (2015). How do learners experience joint writing: University students conceptions of online collaborative writing tasks and environments. Computers \& Education, 82, 393-408. doi:10.1016/j. compedu.2014.11.024

Liu, M., Calvo, R. A., \& Pardo, A. (2013). Tracer: A tool to measure and visualize student engagement in writing activities. Proceedings of the 2013 IEEE 13th International Conference on Advanced Learning Technologies ICALT'13 (pp. 421-425). doi:10.1109/ICALT.2013.129

Lonn, S., Krumm, A. E., Waddington, R. J., \& Teasley, S. D. (2012). Bridging the Gap from Knowledge to Action: Putting Analytics in the Hands of Academic Advisors. Proceedings of the International Conference on Learning Analytics and Knowledge (pp. 184-187). ACM Press. doi:10.1145/2330601.2330647 
Mazza, R., \& Dimitrova, V. (2007). CourseVis: A graphical student monitoring tool for supporting instructors in web-based distance courses. International Journal of Human-Computer Studies, 65(2), 125-139. doi:10.1016/j. ijhcs.2006.08.008

Mckay, T., Miller, K., \& Tritz, J. (2012). What to do with actionable intelligence: E2Coach As An Intervention Engine. Computer. doi:10.1145/2330601.2330627

Noel, S., \& Robert, J.-M. (2004). Empirical Study on Collaborative Writing. Computer Supported Cooperative Work, 13(1), 63-89. doi:10.1023/B:COSU.0000014876.96003.be

Popescu, E., Maria, C., \& Loredana, A. (2014). Fostering Collaborative Learning with Wikis: Extending MediaWiki with Educational Features. Proceedings of the International Conference on Web-Based Learning 2014 (pp. 22-31). Springer.

Posner, I. R., \& Baecker, R. M. (1992). How People Write Together. Proceedings of the Twenty-Fifth Annual Hawaii International Conference on System Sciences (pp. 127-138). doi:10.1109/HICSS.1992.183420

Rivera-Pelayo, V., Munk, J., Zacharias, V., \& Braun, S. (2013). Live interest meter: learning from quantified feedback in mass lectures. Proceedings of the Third International Conference on Learning Analytics and Knowledge, Leuven, Belgium (pp. 23-27). doi:10.1145/2460296.2460302

Roberts, T. S., \& McInnerney, J. M. (2007). Seven Problems of Online Group Learning (and Their Solutions). Educ. Technol. Soc., 10, 257-268.

Sharples, M. (1993). Adding a Little Structure to Collaborative Writing. In D. Diaper \& C. Sanger (Eds.), CSCW in Practice: An Introduction and Case Studies (pp. 51-67). London, UK: Springer-Verlag. doi:10.1007/978-14471-2009-4_5

Southavilay, V., Yacef, K., Reimann, P., \& Calvo, R. A. (2013). Analysis of Collaborative Writing Processes Using Revision Maps and Probabilistic Topic Models. Proceedings of the 3rd ACM International Conference on Learning Analytics and Knowledge (pp. 38-47). doi:10.1145/2460296.2460307

Storch, N. (2002). Patterns of Interaction in ESL Pair Work. Language Learning, 52(1), 119-158. doi:10.1111/1467-9922.00179

Stromqvist, S., \& Malmsten, L. (1998). ScriptLog Pro 1.04.

Tanes, Z., Arnold, K. E., King, A. S., \& Remnet, M. A. (2011). Using Signals for appropriate feedback: Perceptions and practices. Computers \& Education, 57(4), 2414-2422. doi:10.1016/j.compedu.2011.05.016

Theis, J., Wells, K., Schmidt, J., \& Klaetsch, L. (2010). Changeset Protocol. PolicyPad Doc. Retrieved from http://policypad.readthedocs.org/en/latest/changesets.html

Verbert, K., Duval, E., Klerkx, J., Govaerts, S., \& Santos, J. L. (2013). Learning Analytics Dashboard Applications. The American Behavioral Scientist, 57(10), 1500-1509. doi:10.1177/0002764213479363

Verpoorten, D., Westera, W., \& Specht, M. (2011). A first approach to "Learning Dashboards." Proceedings of the 1st International Workshop on Enhancing Learning with Ambient Displays and Visualization Techniques.

Waddington, R. J., \& Teasley, S. D. (2016). Improving Early Warning Systems with Categorized Course Resource Usage. J. Learn. Anal., 3(3), 263-290. doi:10.18608/jla.2016.33.13

Wheeler, S., Yeomans, P., \& Wheeler, D. (2008). The good, the bad and the wiki: Evaluating student-generated content for collaborative learning. British Journal of Educational Technology, 39(6), 987-995. doi:10.1111/j.14678535.2007.00799.x

Zhang, F., \& Litman, D. J. (2014). Sentence-level Rewriting Detection. Proceedings of the 9th Workshop on Innovative Use of NLP for Building Educational Applications. Baltimore, Maryland: ACL. doi:10.3115/v1/ W14-1818 
Ming Liu is Associate Professor at the School of Computer and Information Science, Southwest Universi-ty, China. He received the PhD in Artificial Intelligence in Education at the School of Electrical and Information Engineering, The University of Sydney, Australia in 2012. His main research interests include learning analytics and intelligent tutoring system. He participated in national and international projects funded by ARC Linkage (Aus-tralia), Young and Well CRC, Office of Teaching and Learning, Google and Chinese National Fund. He is an author of over 14 publications papers in prestigious conferences and journals, such as Intelligent Tutoring Systems, IEEE transactions on Learning Technologies, Journal of Educational Technology and Society.

Abelardo Pardo is Associate Professor in the School of Electrical and Information Engineering at The University of Sydney, Australia. He is the director of the Learning and Affect Technologies Engineering Research Laboratory. His research interests include the design and deployment of technology to increase the understanding and improve digital learning experiences. More specifically, his work examines the areas of learning analytics, personalized active learning, and technology for student support.

Li Liu is associate professor at Chongqing University. He is also serving as a Senior Research Fellow of School of Computing at the National University of Singapore. Li received his Ph.D. in Computer Science from the Univer-sité Paris-sud XI in 2008. He had served as an associate professor at Lanzhou University in China. His research interests are in pattern recognition, data analysis, and their applications on human behaviors. He aims to contribute in interdisciplinary research of computer science and human related disciplines. Li has published widely in conferences and journals with more than 60 peer-reviewed publications. Li has been the Principal Investigator of several funded projects from government and industry. 